\title{
Expression patterns of regulatory IncRNAs and miRNAs in muscular atrophy models induced by starvation in vitro and in vivo
}

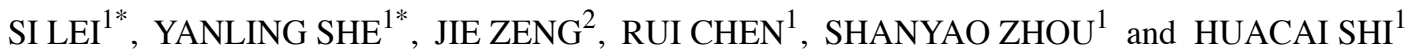 \\ ${ }^{1}$ Guangdong Traditional Medical and Sports Injury Rehabilitation Research Institute, \\ Guangdong Second Provincial General Hospital, Guangzhou, Guangdong 510317; \\ ${ }^{2}$ Department of Medical Ultrasonics, The Third Affiliated Hospital, Sun Yat-Sen University, \\ Guangzhou, Guangdong 510630, P.R. China
}

Received March 13, 2019; Accepted July 30, 2019

DOI: $10.3892 / \mathrm{mmr} .2019 .10661$

\begin{abstract}
Starvation or severe deprivation of nutrients, which is commonly seen in surgical patients, can result in catabolic changes in skeletal muscles, such as muscle atrophy. Therefore, it is important to elucidate the underlying molecular regulatory mechanisms during skeletal muscle atrophy. In the present study, muscular atrophy was induced by starvation and the results demonstrated that myosin heavy chain was decreased, whereas muscle RING finger protein 1 and atrogin-1 were increased, both in vitro and in vivo. The impact of starvation on the expression patterns of long non-coding RNAs (lncRNAs) and microRNAs (miRNAs) was next determined. The expression patterns of miR-23a, miR-206 and miR-27b in the starved mice exhibited similar trends as those in starved $\mathrm{C} 2 \mathrm{C} 12$ cells in vitro, whereas the expression patterns of six other miRNAs (miR-18a, miR-133a, miR-133b, miR-186, miR-1a and miR-29b) differed between the in vivo and the in vitro starvation models. The present study indicated that in vitro expression of the selected miRNAs was not completely consistent with that in vivo. By contrast, lncRNAs showed excellent consistency in their expression patterns in both the in vitro and in vivo starvation models; six of the lncRNAs (Atrolnc-1, long intergenic non-protein coding RNA of muscle differentiation 1, Myolinc, lncRNA myogenic differentiation 1, Dum and muscle anabolic regulator 1) were significantly elevated in starved tissues and cells, while lnc-mg was significantly decreased, compared with the control groups. Thus, IncRNAs involved in muscle atrophy have the potential to be developed as diagnostic tools.
\end{abstract}

Correspondence to: Dr Rui Chen, Guangdong Traditional Medical and Sports Injury Rehabilitation Research Institute, Guangdong Second Provincial General Hospital, 466 Xin Gang Zhong Road, Guangzhou, Guangdong 510317, P.R. China

E-mail: rui.c.med@163.com

*Contributed equally

Key words: long non-coding RNAs, microRNAs, atrophy, starvation, skeletal muscle

\section{Introduction}

Starvation or severe deprivation of nutrients, which is commonly seen in surgical patients, can result in various adaptive and catabolic changes in skeletal muscles, such as muscle atrophy $(1,2)$. Except starvation and fasting, multiple physiological and pathological conditions, including immobilization, mechanical unloading, cancer and chronic disease, can also trigger muscle atrophy $(3,4)$. Our previous studies demonstrated that decreases in actin fiber size resulted in reduced expression of myogenin, and elevated expression of atrogin-1 induced by cobalt dichloride mimicking hypoxia, which subsequently led to skeletal muscle atrophy $(5,6)$.

Muscle atrophy is usually accompanied by a decrease in skeletal muscle mass, an important prognostic indicator of many diseases. Patients with muscular atrophy often have increased morbidity and mortality (7). Decreased muscle protein synthesis accounts predominantly for skeletal muscle atrophy. There are several protective and therapeutic measures against muscular atrophy, such as intake of essential amino acids (8), insulin-like growth factor (IGF)-I treatment (9) and anabolic androgenic steroids (10); however, these measures can cause increased drug resistance and cardiac events, limiting their therapeutic utility for the treatment of muscle atrophy $(4,11)$. Although major advances in our understanding of protein loss in muscle atrophy have been made recently (12-15), it is important to elucidate the underlying molecular regulatory mechanisms of dysfunctional muscle anabolism during skeletal muscle atrophy, in order to develop promising strategies to prevent and treat muscular atrophy.

Long non-coding RNAs (lncRNAs) are a class of non-coding RNAs $>200$ nucleotides in length that make up the majority of the transcriptome $(16,17)$. IncRNAs have emerged as significant regulators in multiple physiological and pathological processes. IncRNAs have important roles in skeletal muscle differentiation, development and muscular atrophy $(3,18-24)$ through various mechanisms, such as competitive endogenous RNA and cis- and trans-regulatory mechanisms $(4,17,18,20,23,25)$. Long intergenic non-protein coding RNA muscle differentiation 1 (lincMD1) regulates the expression of mastermind like transcriptional coactivator 1 and myocyte enhancer factor $2 \mathrm{C}$ in the muscle differentiation 
program (18). Myogenesis-associated lncRNA (lnc-mg) regulates IGF-2, myosin heavy chain (MYHC), lactamase $\beta$ and myogenic differentiation factor to control muscle differentiation and development $(24,26)$. MYHC is a crucial component of myosin, which participates in the formation of the cytoskeleton and provides a force for muscular contraction. Atrolnc-1 causes increased expression of muscle RING finger protein 1 (MURF1), leading to myofiber atrophy in mice with chronic kidney disease (3). The abnormal expression of lncRNAs can result in various pathologies, including cancer, and cardiac and muscle diseases $(27,28)$. Although mechanisms involving the obvious functions of lncRNAs continue to be identified, few studies have provided a comprehensive perspective of lncRNAs in terms of their functions in skeletal muscle atrophy.

MicroRNAs (miRNAs, 22 nucleotides in length) constitute a class of highly conserved, small endogenous non-coding RNA molecules that negatively regulate gene expression at the post-transcriptional level (29-32). Most miRNAs are ubiquitously expressed. Some miRNAs are mainly expressed in muscle but may also be observed at low levels in other tissues. These miRNAs have important roles in muscle differentiation, development and atrophy (33-35), and are predicted to participate in the regulatory networks of myogenesis, muscle fiber type composition, muscle growth and homeostasis (33). The miRNAs associated with muscle differentiation, development and muscular atrophy include miR-133a (36,37), miR-133b (38), miR-206 $(39,40)$, miR-186 (41), miR-23a (42,43), miR-27b (44), miR-29b (32), miR-1a (39) and miR-18a $(45,46)$. miR-1 promotes myoblast differentiation and regeneration $(36,37,39,47)$. miR-29b is required for loss of muscle mass in cases of dexamethasone, tumor necrosis factor- $\alpha$ and $\mathrm{H}_{2} \mathrm{O}_{2}$ treatment-induced muscle atrophy (32). Given the crucial roles of miRNAs in muscle proliferation and differentiation, changes in their regulation, and their potential involvement in muscle atrophy during starvation, could be expected. Changes in the expression of muscle development-associated miRNAs in a disease state may induce muscle atrophy, however it is unclear whether these miRNAs are causally involved in adaptive or compensatory responses to muscle atrophy (33).

lncRNAs and miRNAs are both non-coding RNAs, of which miRNAs have been extensively investigated in skeletal muscle development (32,33,35-47). An increasing number of studies has demonstrated that IncRNAs are also involved in skeletal muscle development (3,18,20-23). IncRNAs and miRNAs can mutually restrict muscle development. IncRNA H19 modulates let-7 availability by acting as a molecular sponge. H19 depletion leads to accelerated muscle differentiation, indicating that this lncRNA counteracts muscle differentiation (48). IncRNA Sirtl antisense fully bound to sirtuin 1 mRNA forms an RNA duplex that promotes myoblast proliferation and inhibits differentiation by competing with miR-34a (49). Few studies have provided a comprehensive perspective of lncRNAs and miRNAs in terms of their regulation of skeletal muscle atrophy. Therefore, the present study aimed to investigate the expression levels of regulatory lncRNAs and miRNAs in mice with muscular atrophy induced by starvation in vitro and in vivo.

In the present study, a serum starvation $\mathrm{C} 2 \mathrm{C} 12$ cell model and a starved muscular atrophy mouse model were established, and analyzed by reverse transcription-quantitative PCR (RT-qPCR), western blot analysis, immunofluorescence staining and hematoxylin and eosin (H\&E) staining. Subsequently, lncRNAs and miRNAs associated with muscle differentiation or atrophy, whose expression trends in the muscle differentiation or atrophy models were consistent with the findings of previous studies $(3,18-24,32,33,35-47)$, were selected to identify differences of regulatory non-coding RNA expression. The current findings indicated that lncRNAs showed similar expression trends in vitro and in vivo and may have great potential as a diagnostic tool.

\section{Materials and methods}

Cell culture. The mouse myoblast $\mathrm{C} 2 \mathrm{C} 12$ cell line was purchased from the Stem Cell Bank of the Type Culture Collection of the Chinese Academy of Sciences and cultured at $37^{\circ} \mathrm{C}$ in $5 \% \mathrm{CO}_{2}$ and high-glucose Dulbecco's modified Eagle's medium (cat. no. 12100046; Gibco; Thermo Fisher Scientific, Inc.) supplemented with $10 \%(\mathrm{v} / \mathrm{v})$ fetal bovine serum (cat. no. SH30070.03; HyClone; GE Healthcare Life Sciences). For myotube differentiation, $\mathrm{C} 2 \mathrm{C} 12$ myoblasts were incubated in 12-well plates with $2 \%$ horse serum (cat. no. SH30074.03; HyClone; GE Healthcare Life Sciences) for 72 h, according to previous studies $(17,50)$. For starvation studies, the medium of the differentiated myotubes was replaced with serum-free medium for an additional $48 \mathrm{~h}$ (51).

Mouse strains and starvation-induced muscular atrophy model. Male C57BL/6 mice (age, 6 weeks; weight, 20-22 g) were acquired from the Animal Laboratory of Sun Yat-sen University (Guangzhou, China). Mice were maintained under standard conditions of $22 \pm 2^{\circ} \mathrm{C}$ at a relative humidity of $50-60 \%$ and housed under alternate $12 \mathrm{~h}$ dark/light cycle conditions. Mice were allowed free access to food and drinking water. All animal procedures were in accordance with the Suggestions for the Care and Use of Laboratory Animals of the Ministry of Science and Technology of the People's Republic of China (52). The study was approved by the Ethics Committee of Guangdong Second Provincial General Hospital (no. 2019-YJSWZ-001).

Following a seven-day acclimation period, the mice were randomly divided into two groups ( $n=6$ mice per group): The starvation/fasting model group and the control group. The starvation/fasting-induced muscular atrophy model group was generated by giving mice access to drinking water for $48 \mathrm{~h}$ only, whereas the control group mice had access to food and drinking water. The humane endpoint used in the present study was body weight loss no more than $20 \%$. The mice exhibited normal grooming and the total body weight loss was $<20 \%$ when the mice were sacrificed. Mice were weighed and sacrificed by cervical dislocation under terminal anesthesia by inhalation of isoflurane, and tibialis anterior muscles were dissected, weighed and placed in $4 \%$ neutral formalin fixative solution for $24 \mathrm{~h}$ at $25^{\circ} \mathrm{C}$, or immediately snap frozen in liquid nitrogen before storing at $-80^{\circ} \mathrm{C}$.

\section{RNA extraction and RT- $q P C R$}

Isolation of RNA from cultured C2C12 cells. For in vitro analyses, cell samples were washed with PBS before lysis in TRIzol reagent (cat. no. 15596018; Thermo Fisher 
Table I. Sequences of mRNA and long non-coding RNA primers.

\begin{tabular}{lll}
\hline Gene & \multicolumn{1}{c}{ Forward primer $\left(5^{\prime}-3^{\prime}\right)$} & \multicolumn{1}{c}{ Reverse primer $\left(5^{\prime}-3^{\prime}\right)$} \\
\hline $18 \mathrm{~S}$ & GTAACCCGTTGAACCCCATT & CCATCCAATCGGTAGTAGCG \\
MURF1 & GTGTGAGGTGCCTACTTGCTC & GCTCAGTCTTCTGTCCTTGGA \\
Atrogin-1 & GAGTGGCATCGCCCAAAAGA & TCTGGAGAAGTTCCCGTATAAGT \\
Atrolnc-1 & CAGCTGCCTACACCTGAAGA & AGGGCTCGCAGATTACACC \\
lincMD1 & AGTGATTGAGGTGGACAGAAGG & CCCATTGAGGAGCATAGAACC \\
Myolinc & CGGTGCTATGGTTCTGATCG & TATGTGGGAAATACAGGGACA \\
LncMyoD & ACCCAAGGCAAGAAAAGTAGCA & ACTCACGAGTCAGCGGCAGAAC \\
Dum & CACAAAGACAGGCAGACAGAC & TACCAAGCAGGTTCCTACGG \\
MAR1 & CCAAAGGACTGTCTTGGAACA & AACAGCACTGAGCAGGGAC \\
lnc-mg & CTGCATCACGGAAGGAGATA & AACAATCCATCCTCATTGGC
\end{tabular}

LincMD1, long intergenic non-protein coding RNA muscle differentiation 1; lnc-mg, myogenesis-associated lncRNA; MAR1, muscle anabolic regulator 1 .

Scientific, Inc.). RNA extraction was performed according to the manufacturer's instructions.

Isolation of RNA from tibialis anterior muscles. Frozen tibialis anterior muscles were lysed in TRIzol reagent (Thermo Fisher Scientific, Inc.) and homogenized with a tissue homogenizer (Shanghai Jingxin Industrial Development Co., Ltd.). RNA extraction was performed as described above.

$R T-q P C R$. For mRNA and lncRNA detection, total RNA was reverse-transcribed into cDNA using the PrimeScript RT Master mix (cat. no. RR036A; Takara Bio, Inc.). For miRNA detection, total RNA was reverse-transcribed into cDNA using the Mir-X ${ }^{\mathrm{TM}}$ miRNA First-Strand Synthesis kit (cat. no. 638313; Takara Bio, Inc.). The abundance of mRNAs, IncRNAs and miRNAs was measured with SYBR-Green Mix (cat. no. RR820A; Takara Bio, Inc.) on a StepOne Plus Real-Time PCR System (Applied Biosystems; Thermo Fisher Scientific, Inc.). PCR for detecting mRNAs and lncRNAs was performed as follows: Denaturation at $95^{\circ} \mathrm{C}$ for $30 \mathrm{sec}$, followed by 40 cycles of denaturation at $95^{\circ} \mathrm{C}$ for $5 \mathrm{sec}$, annealing at $55^{\circ} \mathrm{C}$ for $30 \mathrm{sec}$, and extension at $72^{\circ} \mathrm{C}$ for $30 \mathrm{~s}$. PCR for detecting miRNAs was performed as follows: Denaturation at $95^{\circ} \mathrm{C}$ for $10 \mathrm{sec}$, followed by 40 cycles of denaturation at $95^{\circ} \mathrm{C}$ for $5 \mathrm{sec}$, annealing and extension at $60^{\circ} \mathrm{C}$ for $30 \mathrm{sec}$. mRNA and IncRNA expression was normalized to that of 18S RNA, and miRNA expression was normalized to that of U6 using the $2^{-\Delta \Delta \mathrm{Cq}}$ method (53). A universal reverse primer, mRQ 3' Primer (cat. no. 638313; Takara Bio, Inc.), was used for the all the miRNAs. Primer sequences are listed in Tables I and II.

Immunofluorescence staining and myotube diameter measurements. Myotube diameter was analyzed by MYHC staining. Harvested cells were fixed with a $4 \%$ paraformaldehyde solution three times for $10 \mathrm{~min}$ at $25^{\circ} \mathrm{C}$, blocked with goat serum (cat. no. C0265; Beyotime Institute of Biotechnology) for $1 \mathrm{~h}$ at $25^{\circ} \mathrm{C}$, and then incubated with mouse anti-MYHC primary antibody (1:80; cat. no. MAB4470; R\&D Systems, Inc.) overnight at $4^{\circ} \mathrm{C}$. After removing the solution containing the primary antibody, cells were incubated with Alexa
Table II. Sequences of miRNA primers.

\begin{tabular}{ll}
\hline miRNA & \multicolumn{1}{c}{ Sequence (5'-3') } \\
\hline U6 & F: GGAACGATACAGAGAAGATTAGC \\
& R: TGGAACGCTTCACGAATTTGCG \\
miR-133a & TTTGGTCCCCTTCAACCAGC \\
miR-133b & GGTCCCCTTCAACCAGCTA \\
miR-206-3p & GGAATGTAAGGAAGTGTGTGG \\
miR-186 & GAATTCTCCTTTTGGGCTAAAA \\
miR-23a-3p & ATCACATTGCCAGGGATTTCC \\
miR-27b & TTCACAGTGGCTAAGTTCTGC \\
miR-29b-3p & TAGCACCATTTGAAATCAGTGTT \\
miR-1a-3p & TGGAATGTAAAGAAGUATGTAT \\
miR-18a & GCCATCTAGTGCAGATAGAAAA
\end{tabular}

miRNA/miR, microRNA; F, forward; R, reverse.

Fluor 594-conjugated AffiniPure Goat Anti-Mouse IgG (H+L; 1:100; cat. no. AS077; ABclonal Biotech Co., Ltd.) for 1 h. DAPI (cat. no. KGA215; KeyGen Biotech Co., Ltd.) was used to stain nuclei. Images were acquired at magnification, $x 400$ using a fluorescent Leica DMIL LED microscope (Leica Microsystems GmbH). Fiber diameters were measured in randomly selected fields from three different wells of the control and three different wells of the serum-starved myotubes using ImageJ software (v1.44P; National Institutes of Health). Three diameters were measured per myotube, and 80 myotubes were measured per well.

$H \& E$ staining and determining the cross-sectional area (CSA) of muscle fibers. Muscles were placed in neutral formalin fixative solution for $24 \mathrm{~h}$ at $25^{\circ} \mathrm{C}$. To assess tissue morphology, tissues were embedded in paraffin, then $10 \mu \mathrm{m}$ thick transverse sections of tibialis anterior muscles were stained with hematoxylin for $5 \mathrm{~min}$ and eosin for $1 \mathrm{~min}$ (both at $25^{\circ} \mathrm{C}$ ) and sealed with neutral balsam. After H\&E staining, six 
pairs of samples were placed under a microscope at magnification, x200 to capture light microscope images (Leica Microsystems $\mathrm{GmbH}$ ). The obtained images were analyzed by ImageJ software (v1.44P; National Institutes of Health) to measure muscle fiber CSA. The measured data were used to calculate the mean \pm standard deviation.

Western blot analysis. Serum-starved C2C12 myotubes were used to extract total protein. Frozen tibialis anterior muscles were homogenized with a tissue homogenizer (Shanghai Jingxin Industrial Development Co., Ltd.) to extract total protein. RIPA lysis buffer (100 $\mu$; cat. no. P0013D; Beyotime Institute of Biotechnology) was used to extract protein. Equal quantities of protein $(20 \mu \mathrm{g})$, determined using an enhanced Bicinchoninic Acid Protein Assay Kit (cat. no. P0010S; Beyotime Institute of Biotechnology) were separated via 10-12\% SDS-PAGE and transferred onto polyvinylidene fluoride membranes. Membranes were blocked with 5\% non-fat milk for $1 \mathrm{~h}$ at $25^{\circ} \mathrm{C}$ and incubated with primary antibodies targeting MURF1 (1:1,000; cat. no. ab77577; Abcam), atrogin-1 (1:2,000; cat. no. ab168372; Abcam), MYHC (1:1,000; cat. no. MAB4470; R\&D Systems, Inc.) or tubulin (1:5,000; cat. no. AC021; ABclonal Biotech Co., Ltd.) overnight at $4^{\circ} \mathrm{C}$. Tubulin was used as the control for protein quantification. Membranes were then incubated with horseradish peroxide-conjugated goat anti-mouse (1:5,000; cat. no. AS003; ABclonal Biotech Co., Ltd.) or anti-rabbit $(1: 10,000$; cat. no. AS014; ABclonal Biotech Co., Ltd.) secondary antibodies for $1 \mathrm{~h}$ at $25^{\circ} \mathrm{C}$. Band intensity was determined using a chemiluminescent imaging system (Tanon-V8 Pro; Tanon Sciences and Technology, Co., Ltd.). Densitometry was performed to determine protein expression using TanonImage (version 1.00; Tanon Sciences and Technology, Co., Ltd.)

Statistical analysis. GraphPad Prism 5.0 (GraphPad Software, Inc.) was used to perform statistical analyses. Student's t-test was applied for the comparison of two groups. $\mathrm{P}<0.05$ was considered to indicate a statistically significant difference.

\section{Results}

Establishment of the serum starvation C2C12 cell model in vitro. Immunofluorescence staining results indicated that, under serum-starvation conditions, the diameter of starved C2C12 myotubes was thinner compared with control (regularly cultured)myotubes (Fig. 1A and B). The protein expression levels of MYHC were significantly decreased in starved myotubes compared with control myotubes (Fig. 1C). An increase in the transcript and protein expression levels of MURF1 and atrogin-1 were also detected in starved myotubes, by RT-qPCR and western blot analysis respectively (Fig. 1D and E). These results suggested that starvation-induced muscle atrophy was successfully established in C2C12 myotubes.

lncRNA expression patterns in atrophic C2C12 cells. The levels of various IncRNAs associated with muscle development were detected in order to identify differences in regulatory lncRNA expression between control and serum-starved C2C12 cells by RT-qPCR. IncRNAs whose altered expression in the starvation model was consistent with previous studies were selected for subsequent investigation $(3,18-24)$. It was revealed that seven lncRNAs matched these criteria. Six of these lncRNAs [Atrolnc-1, lincMD1, Myolinc, lncMyoD, Dum and muscle anabolic regulator 1 (MAR1)] exhibited significantly increased levels in starved $\mathrm{C} 2 \mathrm{C} 12$ cells compared with control $\mathrm{C} 2 \mathrm{C} 12$ cells (Fig. 2A-F). By contrast, significantly lower lnc-mg levels were observed in starved C2C12 myotubes (Fig. 2G). In the differentiated starved model, the expression levels of lincMD1, Myolinc, LncMyoD, Dum, MAR1, lnc-mg and Atrolnc-1 were significantly different compared with control C2C12, suggesting that these lncRNAs were involved in skeletal muscle differentiation (lincMD1, Myolinc, LncMyoD, Dum, MAR1 and lnc-mg) and atrophy (Atrolnc-1) under starvation conditions.

miRNA expression patterns in atrophic C2C12 cells. As with the IncRNAs, the levels of various miRNAs associated with muscle development were detected in order to identify differences in regulatory miRNA expression between control and serum-starved C2C12 cells by RT-qPCR; miRNAs with expression trends consistent with previous literature $(32,33,35-47)$ were selected for further experiments. It was revealed that nine miRNAs matched these criteria. In starved C2C12 cells, five of the miRNAs (miR-133a, miR-133b, miR-206, miR-186 and miR-23a) exhibited no significant change in expression levels (Fig. 3A-E). Four miRNAs showed different levels of expression between control and serum-starved C2C12 cells. miR-27b and miR-29b expression (Fig. 3F and G) was significantly decreased in starved C2C12 cells; however, miR-1a and miR-18a expression levels were significantly higher (Fig. $3 \mathrm{H}$ and I).

Establishment of a muscular atrophic mouse model induced by starvation in vivo. The ratio of tibial anterior muscle to body weight was decreased significantly in starved mice compared with normally fed control mice (Fig. 4A). H\&E staining revealed that the CSA of mouse tibialis anterior muscles was significantly decreased following food deprivation for $48 \mathrm{~h}$ (Fig. 4B and C). The protein expression levels of MYHC were decreased in starved mouse tibialis anterior muscles compared with control mouse muscles (Fig. 4D). Additionally, the transcript and protein expression levels of MURF1 and atrogin-1 were increased in starved tibialis anterior muscles compared with control mouse muscles (Fig. 4E and F). These results indicated that starvation induced muscle atrophy in mice.

lncRNA expression patterns during mouse starvation. The expression levels of the seven IncRNAs that were selected in the present study were detected in the tibialis anterior muscles of the starved and control mice by RT-qPCR. Six of the IncRNAs (Atrolnc-1, lincMD1, Myolinc, LncMyoD, Dum and MAR1) exhibited significantly higher levels in starved tibialis anterior muscles compared with control muscles (Fig. 5A-F). Significantly lower lnc-mg levels were observed in starved tibialis anterior muscles (Fig. 5G). The differences in the expression levels of the seven lncRNAs in starved mice reflected the patterns of differentiated serum-starved C2C12 cells in vitro. The significantly differential expression of IncRNAs between control and starved mice indicated that these IncRNAs are associated with skeletal muscle proliferation, differentiation and atrophy under starvation conditions. 
A
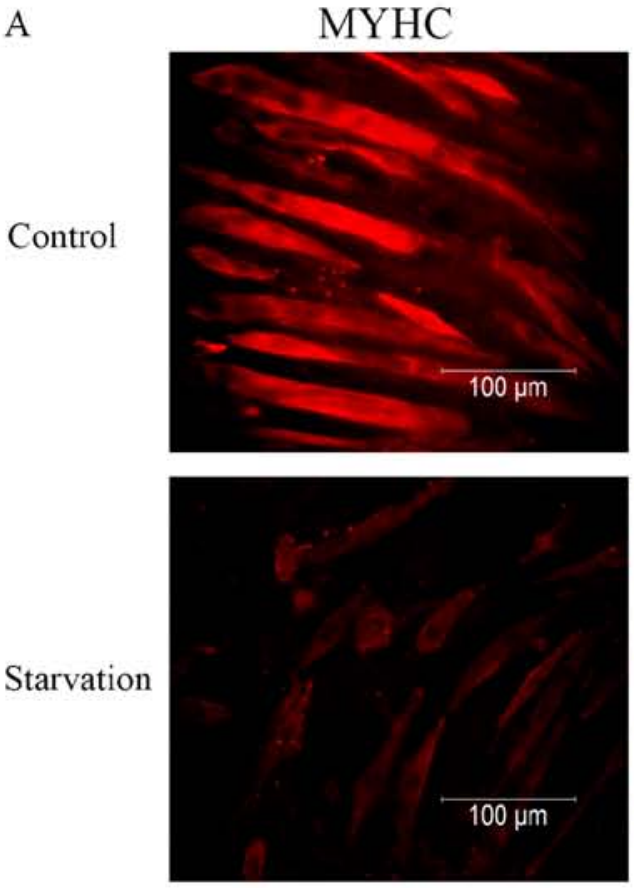

B

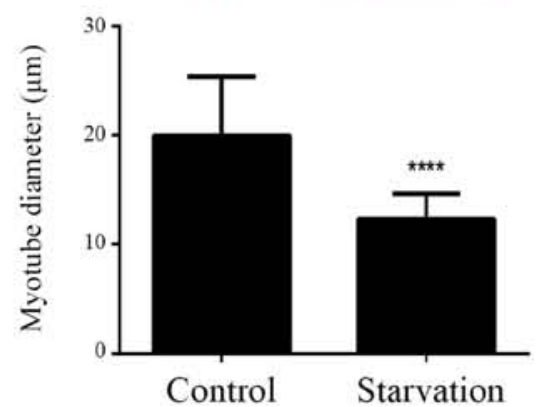

D

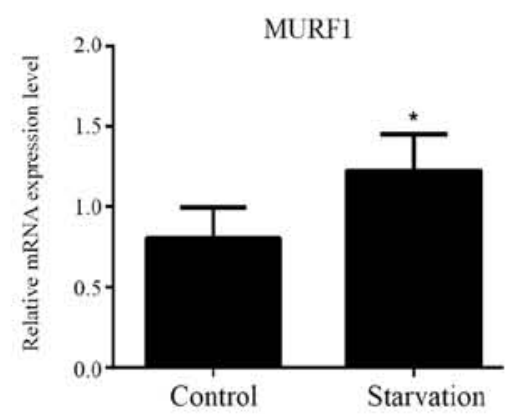

E

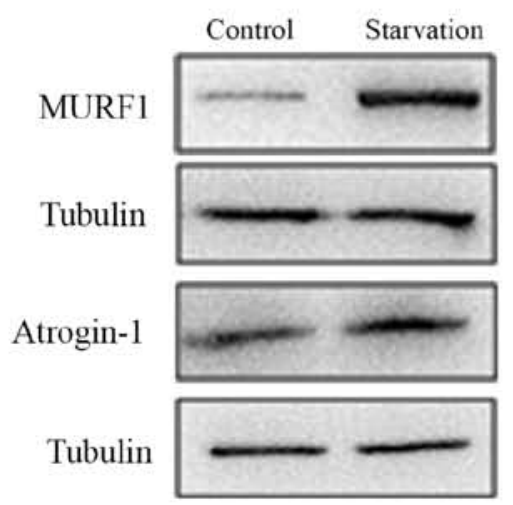

DAPI
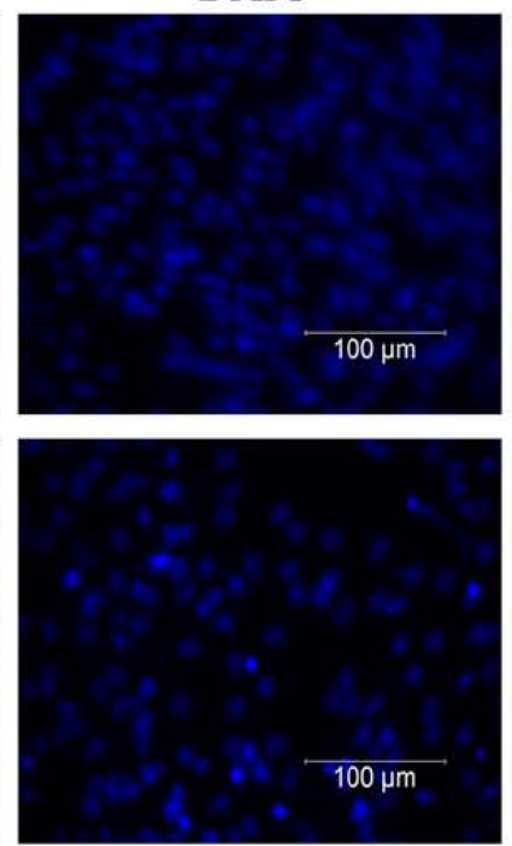

C
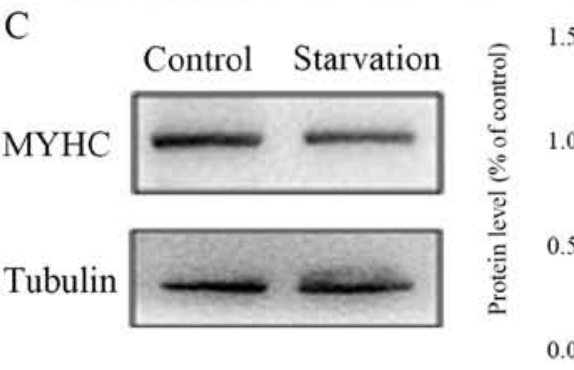

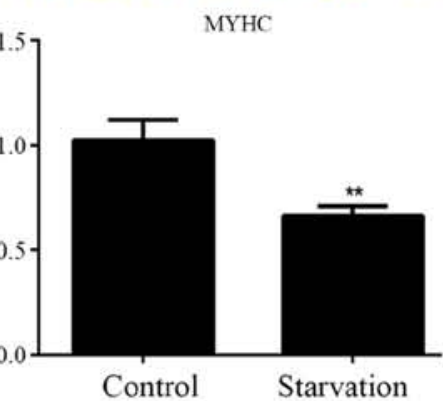

\section{Merged}
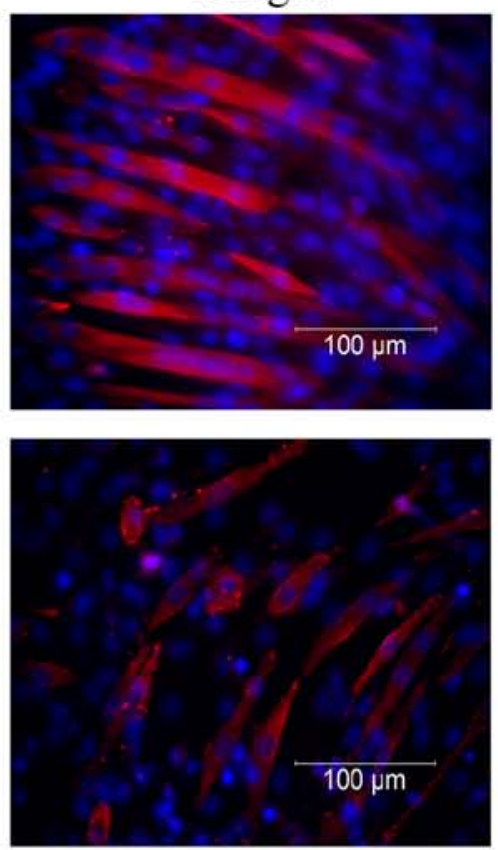

Control

Atrogin-1
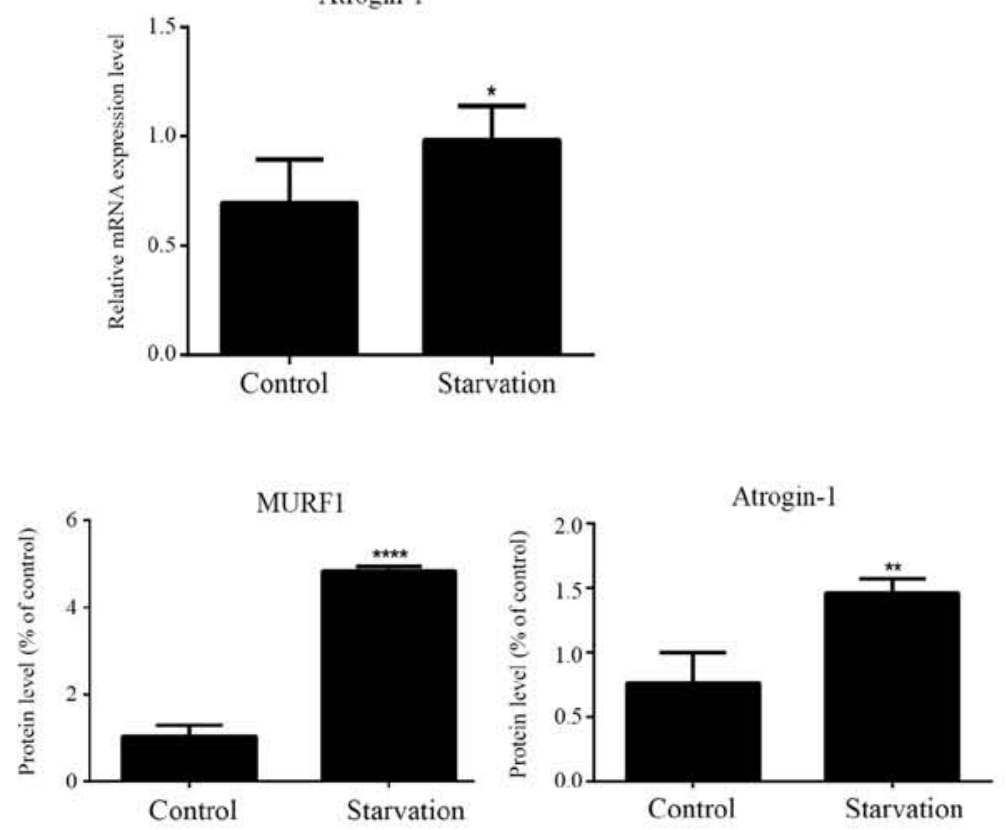

Atrogin-1

Figure 1. Establishment of the serum starvation-induced $\mathrm{C} 2 \mathrm{C} 12$ cell atrophic model in vitro. (A and B) MYHC and DAPI staining showed different myotube diameters between control and serum-starved $\mathrm{C} 2 \mathrm{C} 12$ cells $(\mathrm{n}=3)$. (C) MYHC protein expression levels were detected by western blotting (n=3). (D) mRNA $(\mathrm{n}=6)$ and $(\mathrm{E})$ protein $(\mathrm{n}=3)$ expression levels of MURF1 and atrogin-1 were observed in control and serum-starved $\mathrm{C} 2 \mathrm{C} 12$ cells. ${ }^{*} \mathrm{P}<0.05$, ${ }^{* *} \mathrm{P}<0.01$ and ${ }^{* * * * *} \mathrm{P}<0.0001$. MYHC, myosin heavy chain; MURF1, muscle RING finger protein 1. 

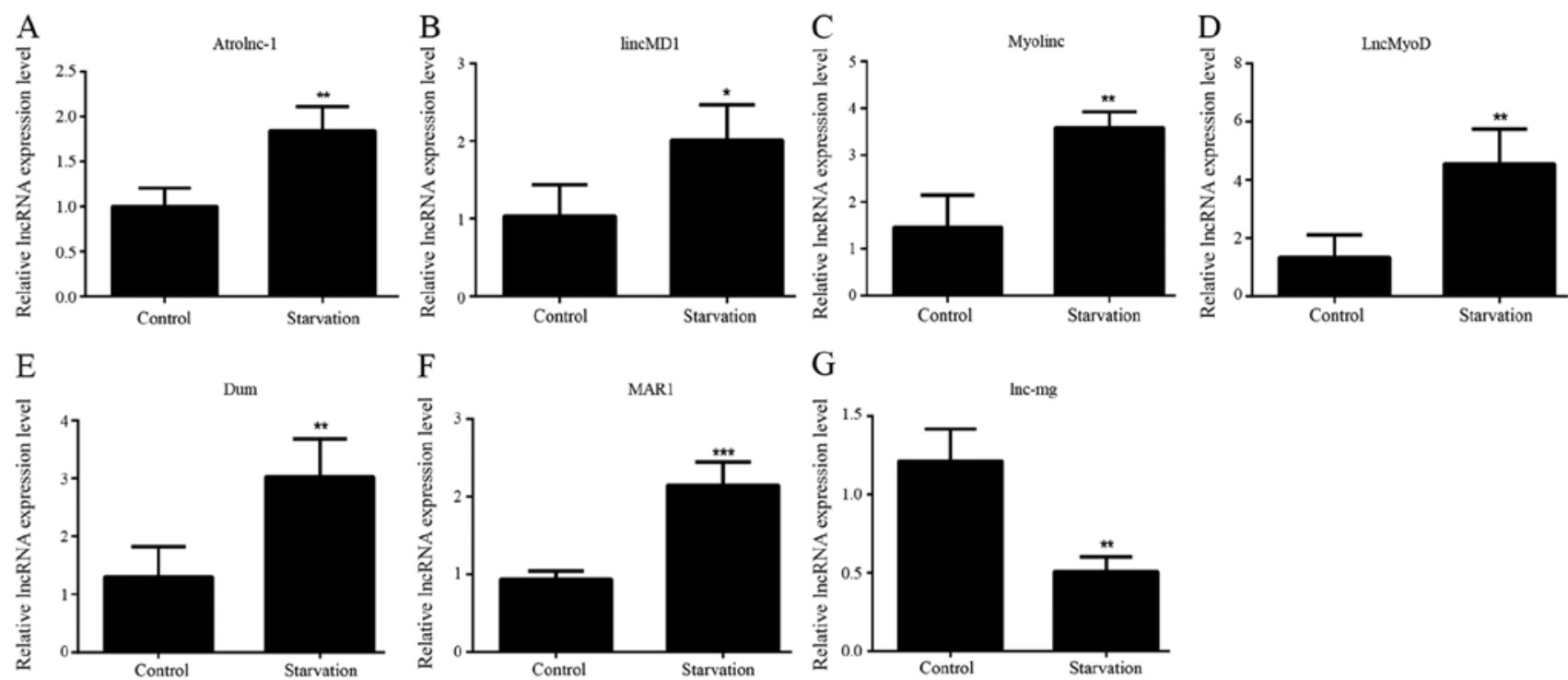

Figure 2. IncRNA expression patterns in serum-starved C2C12 cells. The expression levels of lncRNAs (A) Atrolnc-1, (B) lincMD1, (C) Myolinc, (D) LncMyoD, (E) Dum, (F) MAR1 and (G) lnc-mg were detected in control C2C12 cells and differentiated serum-starved C2C12 cells. All data are presented as the mean \pm standard deviation. ${ }^{*} \mathrm{P}<0.05,{ }^{* * *} \mathrm{P}<0.01$ and ${ }^{* * *} \mathrm{P}<0.001$. $(\mathrm{n}=6)$. lncRNA, long non-coding RNA; lincMD1, long intergenic non-protein coding RNA, muscle differentiation 1; lnc-mg, myogenesis-associated lncRNA; MAR1, muscle anabolic regulator 1.

A

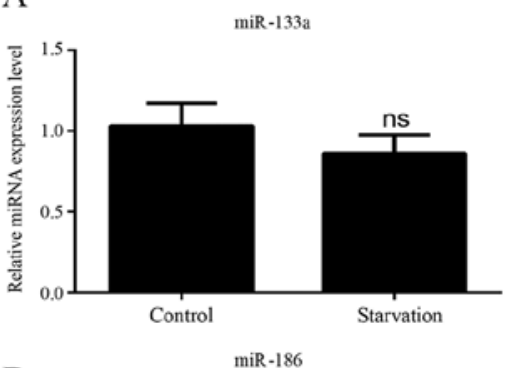

$\mathrm{D}$

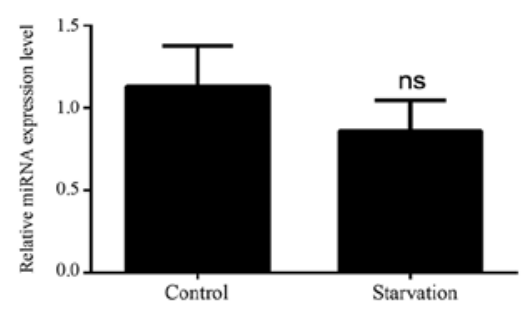

G

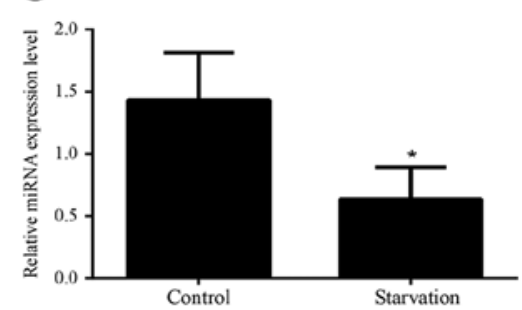

B

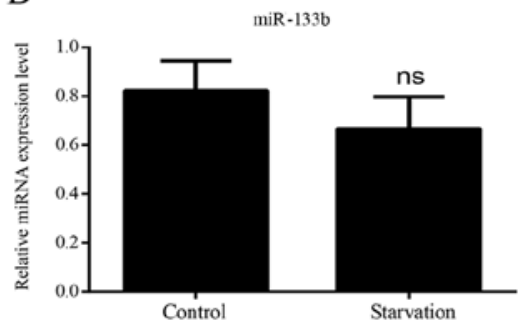

E

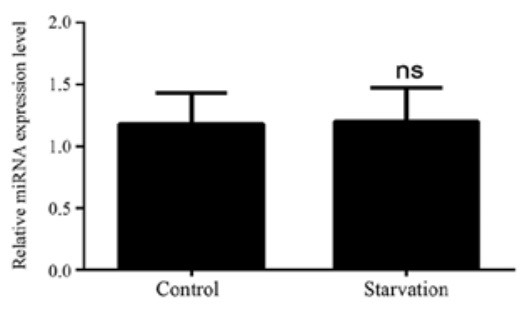

$\mathrm{H}$

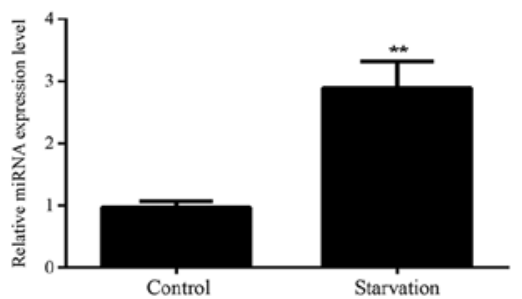

C

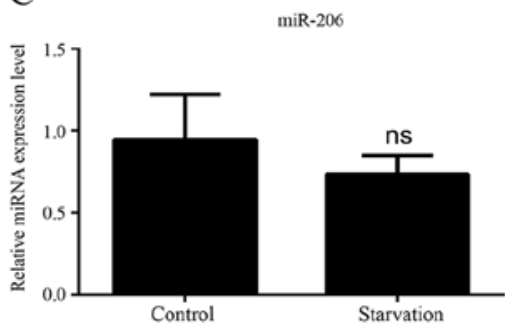

F

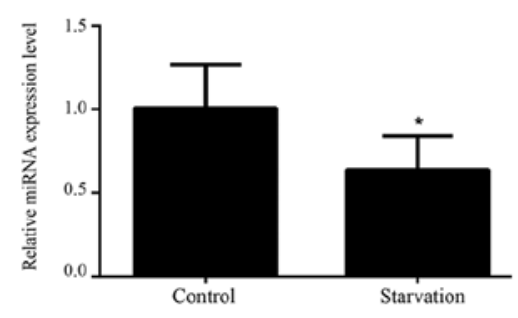

I

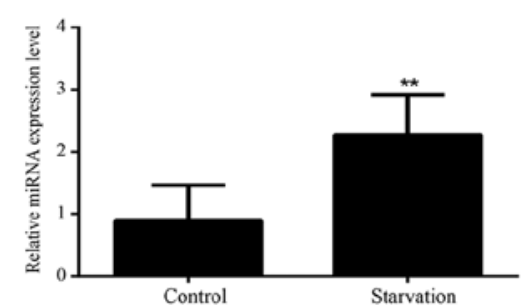

Figure 3. miRNA expression patterns in atrophic C2C12 cells. The expression levels of (A) miR-133a, (B) miR-133b, (C) miR-206, (D) mR-186, (E) miR-23a, (F) miR-27b, (G) miR-29b, (H) miR-1a and (I) miR-18a were detected in control C2C12 cells and serum-starved C2C12 cells. All data are presented as the mean \pm standard deviation. ${ }^{*} \mathrm{P}<0.05$ and ${ }^{* *} \mathrm{P}<0.01(\mathrm{n}=6)$. miRNA/miR, microRNA; ns, no significance.

miRNA expression patterns during mouse starvation. In starved mouse tibialis anterior muscles, three miRNAs (miR-206, miR-23a and miR-18a) showed no significant change in expression levels (Fig. 6C, E and I). Six miRNAs
(miR-133a, miR-133b, miR-186, miR-27b and miR-1a) showed significantly decreased levels of expression, following starvation in mice (Fig. 6A, B, D, F and H). By contrast, the miR-29b expression levels (Fig. 6G) were significantly higher in starved 
A

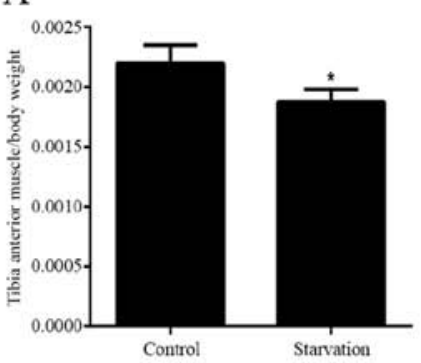

D

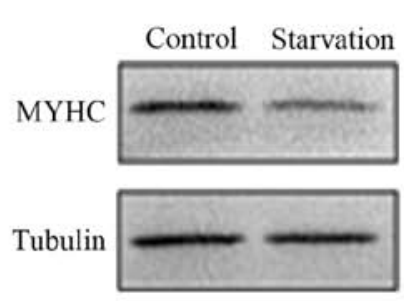

F

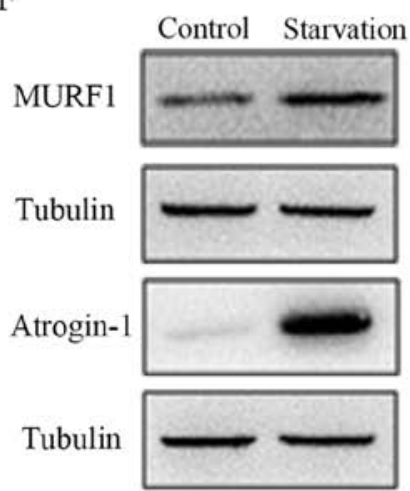

B
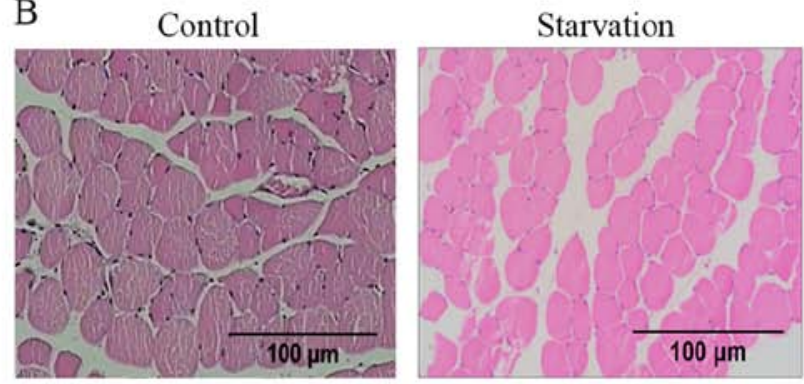

C

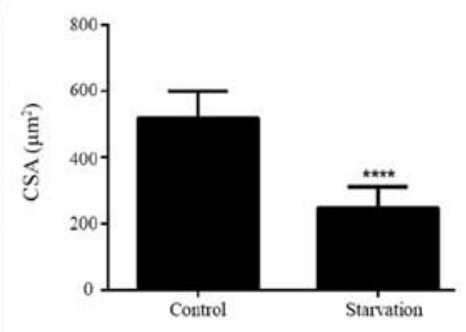

E
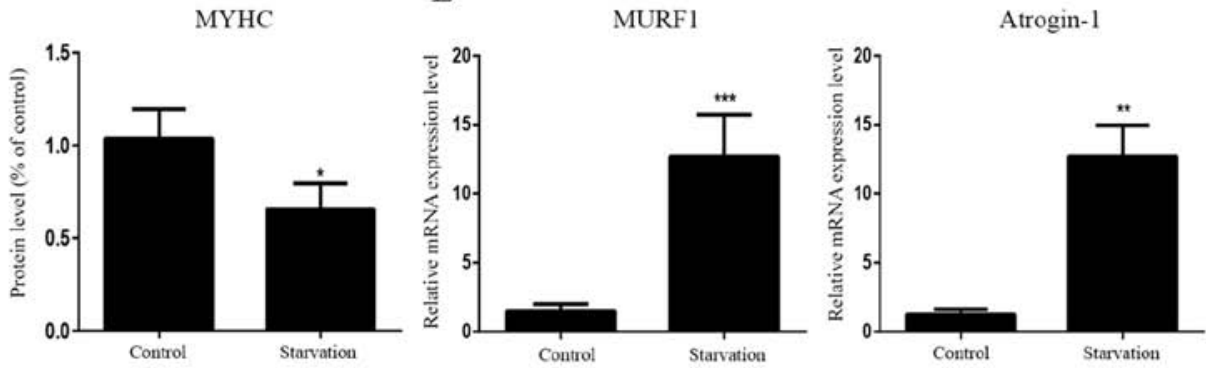

Control

Starvation
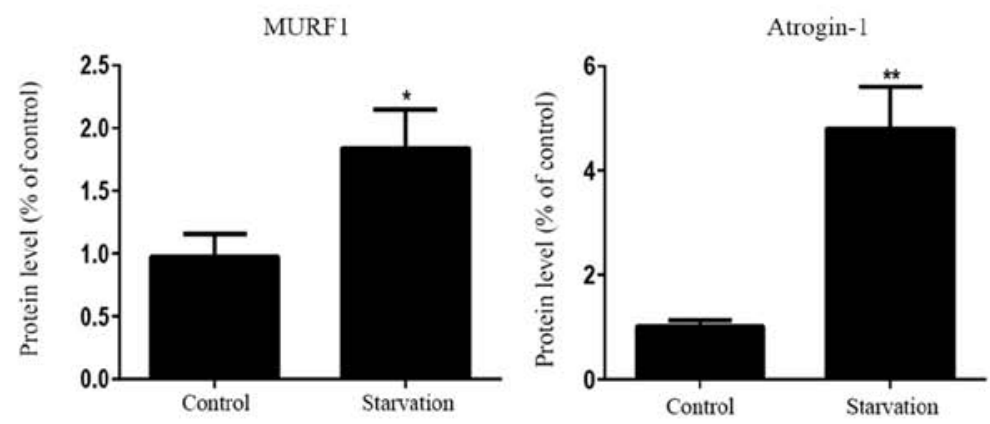

Figure 4. Establishment of the muscular atrophic mouse model induced by starvation in vivo. (A) The ratio of tibial anterior muscle to total body weight decreased in the starved mice. (B and C) Hematoxylin-eosin staining indicates decreased CSA between control and starved tibialis anterior muscles. (D) MYHC protein expression levels were detected by western lot analysis in starved and control tibialis anterior muscles. (E) mRNA and (F) protein expression levels of MURF1 and atrogin- 1 in starved and control tibialis anterior muscles. All data are presented as the mean \pm standard deviation. ${ }^{*} \mathrm{P}<0.05$, $^{* *} \mathrm{P}<0.01$ and ${ }^{* * *} \mathrm{P}<0.001(\mathrm{n}=6)$. MYHC, myosin heavy chain; CSA, cross-sectional area; MURF1, muscle RING finger protein 1.

mice compared with control. The expression patterns of miR-23a, miR-206 and miR-27b in starved mice exhibited the same changes as those of the differentiated serum-starved $\mathrm{C} 2 \mathrm{C} 12$ cells in vitro, whereas the expression patterns of the other six miRNAs differed between the two starvation models.

\section{Discussion}

Muscular atrophy is beginning to be considered in the pathogenesis of many physiological and pathological conditions, such as starvation and severe deprivation of nutrients, muscle disuse, Duchenne progressive muscular dystrophy, cancer and chronic disease. Therefore, it is important to elucidate the molecular regulatory mechanisms underlying dysfunctional muscle anabolism during skeletal muscle atrophy, and to develop strategies to prevent and treat muscular atrophy.

Isolation of muscles from mice revealed few vascular endothelial cells, lymphatic vessels and nerves among the muscle fibers. However, it is difficult at present to purify the skeletal muscle of mice from contamination with endothelial cells or other cell types due to the limitation of current technical tools. Based on other studies on lncRNAs and miRNAs in the skeletal muscle $(19,24,32)$, muscle samples were harvested directly without considering the effects of endothelial cells or any other cell types. Therefore, the entire tibialis anterior muscle was used to explore gene expression and the underlying molecular regulatory mechanisms of muscle dysfunctional metabolism.

Myotube diameter and MYHC intensity are closely associated with skeletal muscle function (54). MYHC participates in the formation of the cytoskeleton and provides the force for muscles to contract normally. In the cell starvation model of the present study, cell myotube diameter was dramatically thinner and MYHC protein expression levels were significantly decreased. Changes in myotube diameter and MYHC expression following starvation may indicate changes in muscle functions.

The present study analyzed the expression patterns of lncRNAs and miRNAs during starvation-induced muscular atrophy in vitro and in vivo. Several lncRNAs, including lnc-mg, Atrolnc-1, lincMD1, Myolinc, lncMyoD, Dum and 

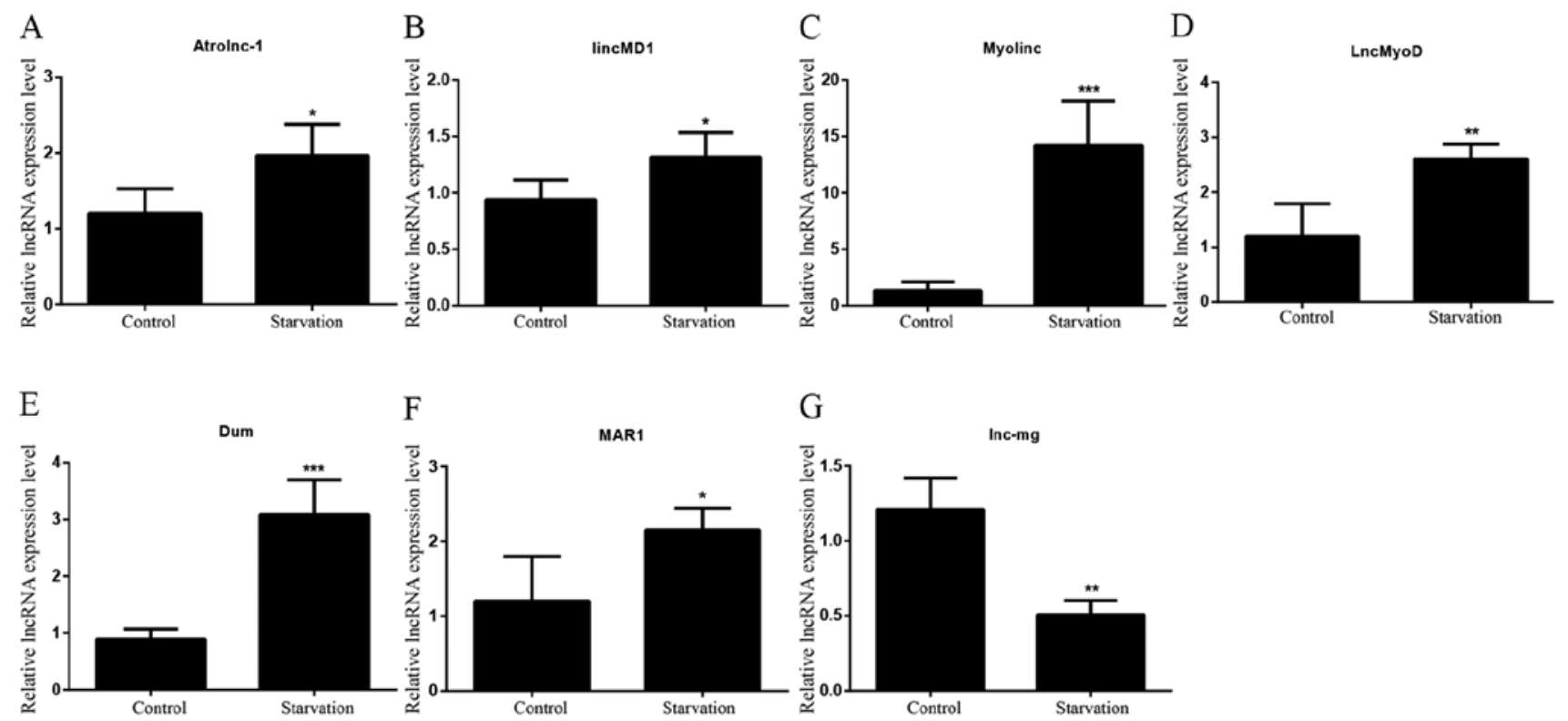

Figure 5. lncRNA expression patterns during mouse starvation. The expression levels of lncRNAs (A) Atrolnc-1, (B) lincMD1, (C) Myolinc, (D) LncMyoD, (E) Dum, (F) MAR1 and (G) lnc-mg were detected in tibialis anterior muscles from normally fed and starved mice. All data are presented as the mean \pm standard deviation. ${ }^{*} \mathrm{P}<0.05,{ }^{* * *} \mathrm{P}<0.01$ and ${ }^{* * * *} \mathrm{P}<0.001$ ( $\mathrm{n}=6$ mice per group). 1ncRNA, long non-coding RNA; lincMD1, long intergenic non-protein coding RNA muscle differentiation 1; lnc-mg, myogenesis-associated lncRNA; MAR1, muscle anabolic regulator 1.

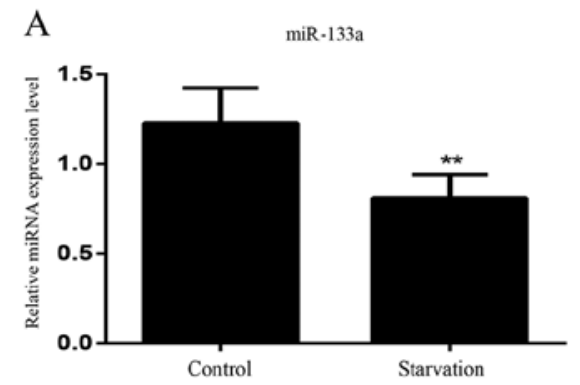

D

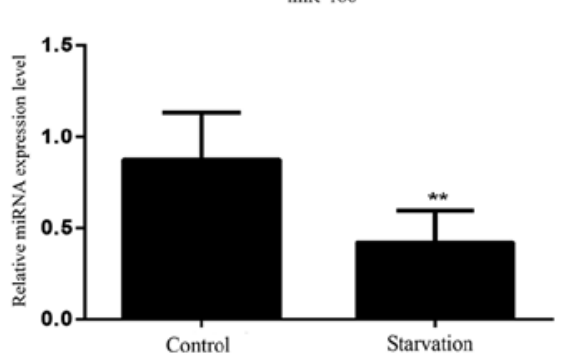

G

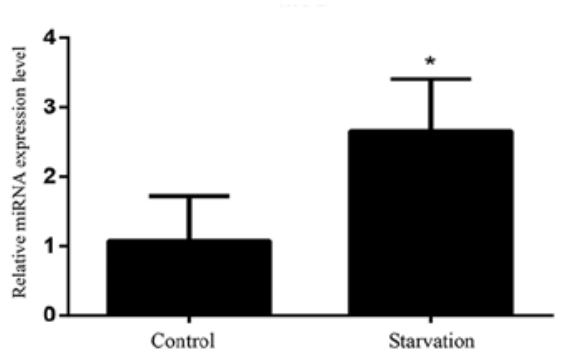

B

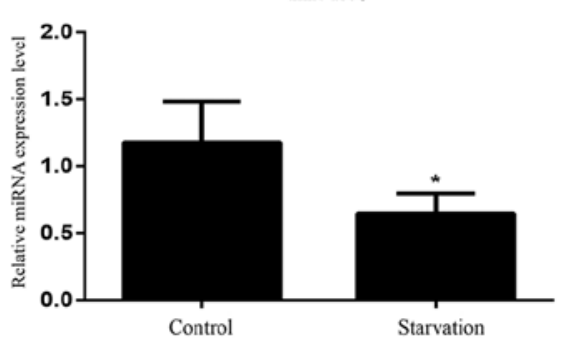

E

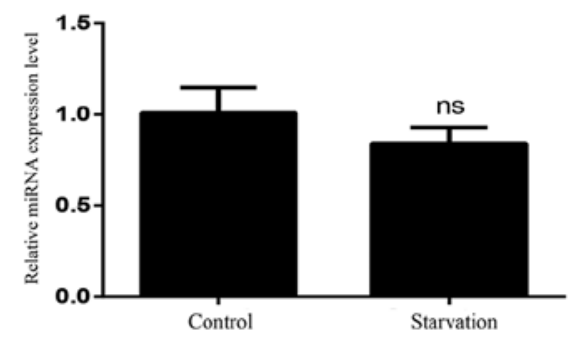

$\mathrm{H}$

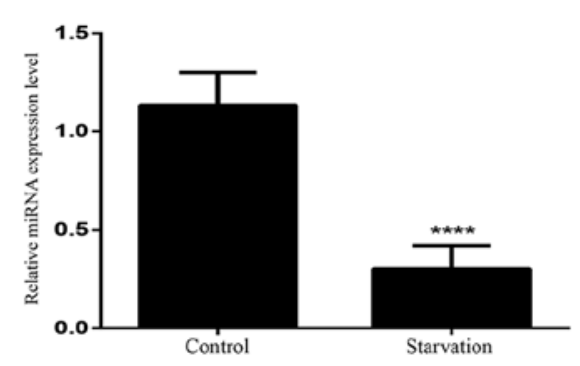

C

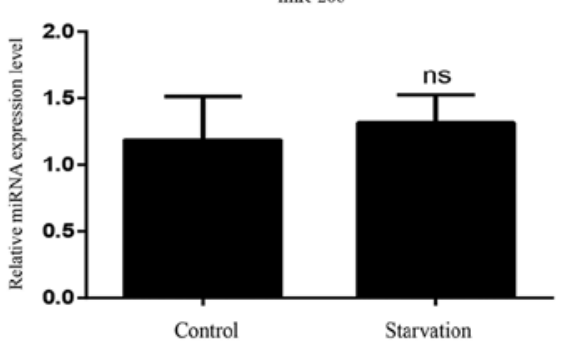

F

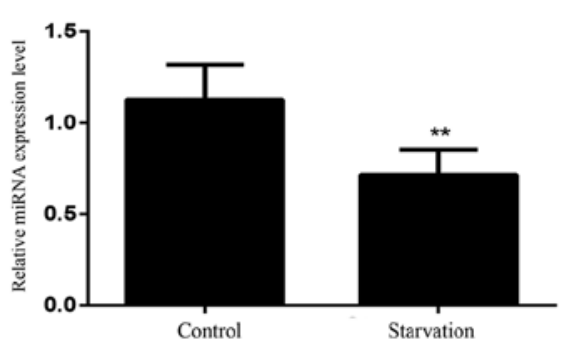

I

miR-18a

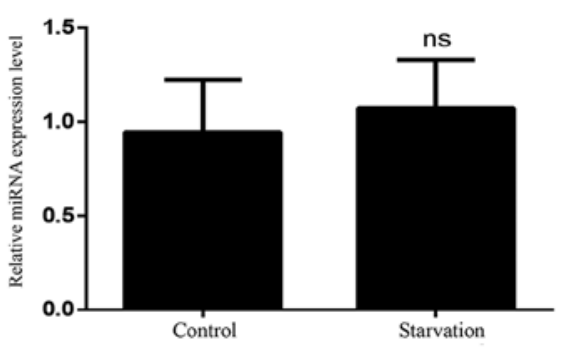

Figure 6. miRNA expression patterns during mouse starvation. The expression levels of (A) miR-133a, (B) miR-133b, (C) miR-206, (D) mR-186, (E) miR-23a, (F) miR-27b, (G) miR-29b, (H) miR-1a and (I) miR-18a were detected in normally fed and starved mice. All data are presented as the mean \pm standard deviation. ${ }^{*} \mathrm{P}<0.05,{ }^{* * *} \mathrm{P}<0.01$ and ${ }^{* * * * *} \mathrm{P}<0.0001$ ( $\mathrm{n}=6$ mice per group). miRNA/miR, microRNA; ns, no significance. 
MAR1 differed in their expression levels between control and atrophic muscles. Lnc-mg (24,26), lincMD1 (18) and Dum (22) regulate the expression of MYHC and have important roles in skeletal muscle cell differentiation and development. Lnc-mg regulates IGF-2 to promote muscle differentiation and development, by functioning as a competitive endogenous RNA for miR-125b (24). In the muscular atrophic models (in vitro and in vivo) of the present study, lnc-mg and MYHC were both decreased. Thus, it is speculated that downregulated lnc-mg may serve an important role in starvation-induced muscular atrophy and could be positively associated with downregulated MYHC. The increased expression of lincMD1 and Dum may be compensatory responses to atrophy. Atrolnc-1 expression was significantly higher in the starvation-induced atrophic models (in vitro and in vivo). This result was consistent with the fact that Atrolnc-1 is remarkably enhanced in atrophic muscles in atrophic mouse models of chronic kidney disease, starvation and cancer (3). Atrolnc-1 interacts with the A20 binding inhibitor of nuclear factor $\kappa \mathrm{B}-1(\mathrm{NF}-\kappa \mathrm{B}-1)$, promoting its activation and resulting in increased MURF1 (3). The high expression of Atrolnc-1 observed in the present study further indicates that muscular atrophy occurred in starved cells and mice.

LincMD1 regulates the expression of mastermind like transcriptional coactivator 1 and myocyte enhancer factor $2 \mathrm{C}$ to promote muscle differentiation by acting as a sponge for miR-133 and miR-135 (18). The present demonstrated that lincMD1 expression levels significantly increased during muscular atrophy, during which myoblasts are required for differentiation and fusion in order to replace damaged myofibers. In addition, lincMD1 promotes the expression of human antigen $\mathrm{R}$ protein to consolidate the muscle regulatory factor mRNAs $(20,55)$. The expression levels of the other four lncRNAs, Myolinc, LncMyoD, Dum and MAR1, were all elevated under atrophic conditions, which may be explained by the fact that myoblasts are required for differentiation and fusion, in order to replace damaged myofibers under atrophic conditions.

The expression patterns of miR-206, miR-23a and miR-27b in starved mice exhibited the same changes as those in differentiated serum-starved $\mathrm{C} 2 \mathrm{C} 12$ cells in vitro, whereas the expression patterns of the other six miRNAs differed between the two starvation models. miR-23a and miR-206 exhibited no significant change in expression levels, indicating that their roles in starvation-induced skeletal muscle atrophy may be minimal. miR-27b promotes muscle differentiation and inhibits proliferation by inhibiting MyoD family inhibitor (MDFI) expression (44). MDFI functions as a negative regulator of muscle growth by inhibiting muscle hypertrophy (56). However, miR-27b expression was significantly decreased in the starvation-induced atrophic models, possibly because differentiation was decreased under atrophic conditions. miR-29b expression in the starvation-induced atrophic mouse model was significantly higher than in control mice, consistent with a study that demonstrated that miR-29b was elevated in an in vivo atrophy model (32). However, the expression of miR-29b in serum-starved C2C12 myotubes in vitro was significantly reduced compared to control myotubes, which was not consistent with our in vivo atrophy model; the role of miR-29b in primary myoblasts therefore remains unclear, which was a limitation of the present study, and the reasons for this phenomenon remain to be determined.

The seven lncRNAs selected exhibited the same expression trends in the in vivo and in vitro starved models. Among the nine miRNAs selected, three miRNAs showed consistent change in trends in the two models, whereas six miRNAs showed inconsistent change. Therefore, the consistency of lncRNA expression was superior; the inconsistent changes in the trends of miRNAs in the two starved models require further investigation.

In conclusion, the present study analyzed the expression patterns of lncRNAs and miRNAs in starvation/fasting-induced muscular atrophy models. The current findings indicated that lncRNAs had similar expression changes in vitro and in vivo. The present results provided a novel insight into the lncRNAs involved in muscle atrophy and suggested that they may serve as potential diagnostic tools. A follow-up investigation is required to better understand the roles of IncRNAs in muscle atrophy.

\section{Acknowledgements}

Not applicable.

\section{Funding}

The current study was supported by grants from the Natural Science Foundation of Guangdong Province (grant no. 2018A030313591), the Science and Technology Planning Project of Guangdong Province (grant no. 2017ZC0333), the Administration of Traditional Chinese Medicine of Guangdong Province (grant no. 20181014), the Science and Technology Planning Project of Haizhu District (grant no. 2018-87), the Science Foundation of Guangdong Second Provincial General Hospital (grant nos. YQ2017-012, YN2017-002, YN2017-003 and YQ2018-005) and the National Natural Science Foundation of China (grant no. 81601503).

\section{Availability of data and materials}

The datasets used and/or analyzed during the current study are available from the corresponding author on reasonable request.

\section{Authors' contributions}

RC conceived and designed the experiments. SL, YS and RC performed the experiments in vivo and analyzed the data. SL, YS, JZ, SZ and HS performed the experiments in vitro and analyzed the data. SL and RC wrote the manuscript. All authors read and approved the final manuscript.

\section{Ethics approval and consent to participate}

The present study was approved by the Ethics Committee of Guangdong Second Provincial General Hospital (approval no. 2019-YJSWZ-001).

\section{Patient consent for publication}

Not applicable. 


\section{Competing interests}

The authors declare that they have no competing interests.

\section{References}

1. Wallimann T, Dolder M, Schlattner U, Eder M, Hornemann T, Kraft T and Stolz M: Creatine kinase: An enzyme with a central role in cellular energy metabolism. MAGMA 6: 116-119, 1998.

2. Zhao C, Shang L, Wang W and Jacobs DO: Myocellular creatine and creatine transporter serine phosphorylation after starvation. J Surg Res 105: 10-16, 2002.

3. Sun L, Si M, Liu X, Choi JM, Wang Y, Thomas SS, Peng H and $\mathrm{Hu} \mathrm{Z}$ : Long-noncoding RNA Atrolnc-1 promotes muscle wasting in mice with chronic kidney disease. J Cachexia Sarcopenia Muscle 9: 962-974, 2018

4. Zhang ZK, Li J, Guan D, Liang C, Zhuo Z, Liu J, Lu A, Zhang G and Zhang BT: Long noncoding RNA IncMUMA reverses established skeletal muscle atrophy following mechanical unloading. Mol Ther 26: 2669-2680, 2018.

5. Chen R, Jiang T, She Y, Xu J, Li C, Zhou S, Shen H, Shi H and Liu S: Effects of cobalt chloride, a hypoxia-mimetic agent, on autophagy and atrophy in skeletal C2C12 myotubes. Biomed Res Int 2017: 7097580, 2017.

6. Chen R, She Y, Fu Q, Chen X, Shi H, Lei S, Zhou S, Ou J and Liu Y: Differentially expressed coding and noncoding RNAs in $\mathrm{CoCl} 2$-induced cytotoxicity of $\mathrm{C} 2 \mathrm{C} 12$ cells. Epigenomics 11: 423-438, 2019.

7. Mak RH, Ikizler AT, Kovesdy CP, Raj DS, Stenvinkel P and Kalantar-Zadeh K: Wasting in chronic kidney disease. J Cachexia Sarcopenia Muscle 2: 9-25, 2011.

8. Zwart SR, Davis-Street JE, Paddon-Jones D, Ferrando AA, Wolfe RR and Smith SM: Amino acid supplementation alters bone metabolism during simulated weightlessness. J Appl Physiol (1985) 99: 134-140, 2005.

9. Alzghoul Mb, Gerrard D, Watkins BA and Hannon K: Ectopic expression of IGF-I and shh by skeletal muscle inhibits disuse-mediated skeletal muscle atrophy and bone osteopenia in vivo. FASEB J 18: 221-223, 2004.

10. Gregory CM, Vandenborne K, Huang HF, Ottenweller JE and Dudley GA: Effects of testosterone replacement therapy on skeletal muscle after spinal cord injury. Spinal Cord 41: 23-28, 2003.

11. Finkle WD, Greenland S, Ridgeway GK, Adams JL, Frasco MA, Cook MB, Fraumeni JF Jr and Hoover RN: Increased risk of non-fatal myocardial infarction following testosterone therapy prescription in men. PLoS One 9: e85805, 2014.

12. Milan G, Romanello V, Pescatore F, Armani A, Paik JH, Frasson L, Seydel A, Zhao J, Abraham R, Goldberg AL, et al: Regulation of autophagy and the ubiquitin-proteasome system by the FoxO transcriptional network during muscle atrophy. Nat Commun 6: 6670, 2015.

13. Cid-Díaz T, Santos-Zas I, González-Sánchez J, GurriaránRodríguez U, Mosteiro CS, Casabiell X, García-Caballero T, Mouly V, Pazos Y and Camiña JP: Obestatin controls the ubiquitin-proteasome and autophagy-lysosome systems in glucocorticoid-induced muscle cell atrophy. J Cachexia Sarcopenia Muscle 8: 974-990, 2017.

14. Miller BF, Baehr LM, Musci RV, Reid JJ, Peelor FF III, Hamilton KL and Bodine SC: Muscle-specific changes in protein synthesis with aging and reloading after disuse atrophy. J Cachexia Sarcopenia Muscle: Jul 16, 2019 (Epub ahead of print). doi: $10.1002 / j \mathrm{jsm} .12470$.

15. Tanaka M, Sugimoto K, Fujimoto T, Xie K, Takahashi T, Akasaka H, Kurinami H, Yasunobe Y, Matsumoto T, Fujino $\mathrm{H}$ and Rakugi H: Preventive effects of low-intensity exercise on cancer cachexia-induced muscle atrophy. FASEB J 33: 7852-7862, 2019

16. Boltaña S, Valenzuela-Miranda D, Aguilar A, Mackenzie S and Gallardo-Escárate C: Long noncoding RNAs (lncRNAs) dynamics evidence immunomodulation during ISAV-Infected Atlantic salmon (Salmo salar). Sci Rep 6: 22698, 2016.

17. Chen R, Jiang T, She Y, Xie S, Zhou S, Li C, Ou J and Liu Y: Comprehensive analysis of lncRNAs and mRNAs with associated co-expression and ceRNA networks in $\mathrm{C} 2 \mathrm{C} 12$ myoblasts and myotubes. Gene 647: 164-173, 2018.

18. Cesana M, Cacchiarelli D and Legnini I, Santini T, Sthandier O, Chinappi M, Tramontano A and Bozzoni I: A long noncoding RNA controls muscle differentiation by functioning as a competing endogenous RNA. Cell 147: 358-369, 2011
19. Gong C, Li Z, Ramanujan K, Clay I, Zhang Y, Lemire-Brachat S and Glass DJ: A long non-coding RNA, LncMyoD, regulates skeletal muscle differentiation by blocking IMP2-mediated mRNA translation. Dev Cell 34: 181-191, 2015.

20. Legnini I, Morlando M, Mangiavacchi A, Fatica A and Bozzoni I: A feedforward regulatory loop between HuR and the long noncoding RNA linc-MD1 controls early phases of myogenesis. Mol Cell 6: 506-514, 2014.

21. Militello G, Hosen MR, Ponomareva Y, Gellert P, Weirick T, John D, Hindi SM, Mamchaoui K, Mouly V, Döring C, et al: A novel long non-coding RNA myolinc regulates myogenesis through TDP-43 and Filip1. J Mol Cell Biol 10: 102-117, 2018.

22. Wang L, Zhao Y, Bao X, Zhu X, Kwok YK, Sun K, Chen X, Huang Y, Jauch R and Esteban MA: LncRNA Dum interacts with Dnmts to regulate Dppa2 expression during myogenic differentiation and muscle regeneration. Cell Res 25: 335-350, 2015.

23. Zhang Z, Li J, Guan D, Liang C, Zhuo Z, Liu J, Lu A, Zhang G and Zhang BT: A newly identified lncRNA MAR1 acts as a miR-487b sponge to promote skeletal muscle differentiation and regeneration. J Cachexia Sarcopenia Muscle 9: 613-626, 2018.

24. Zhu M, Liu J, Xiao J, Yang L, Cai M, Shen H, Chen X, Ma Y, $\mathrm{Hu} \mathrm{S}$, Wang Z, et al: Lnc-mg is a long non-coding RNA that promotes myogenesis. Nat Commun 8: 14718, 2017.

25. Xiong W, Jiang Y, Ai Y, Liu S, Wu XR, Cui JG, Qin JY, Liu Y, $\mathrm{Xia} \mathrm{YX}$ and Ju YH: Microarray analysis of long non-coding RNA expression profile associated with 5-fluorouracil-based chemoradiation resistance in colorectal cancer cells. Asian Pac J Cancer Prev 16: 3395-3402, 2015.

26. Du J, Zhang P, Zhao X, He J, Xu Y, Zou Q, Luo J, Shen L, Gu H, Tang Q, et al: MicroRNA-351-5p mediates skeletal myogenesis by directly targeting lactamase- $\beta$ and is regulated by lnc-mg. FASEB J 33: 1911-1926, 2019.

27. Neguembor MV, Jothi M and Gabellini D: Long noncoding RNAs, emerging players in muscle differentiation and disease. Skelet Muscle 4: 8, 2014.

28. Simionescu-Bankston A and Kumar A: Noncoding RNAs in the regulation of skeletal muscle biology in health and disease. J Mol Med (Berl) 94: 853-866, 2016.

29. Bartel DP: MicroRNAs: Genomics, biogenesis, mechanism, and function. Cell 116: 281-297, 2004.

30. Ivey KN and Srivastava D: MicroRNAs as developmental regulators. Cold Spring Harb Perspect biol 7: a008144, 2015.

31. Lei Z, Sluijter JP and van Mil A: MicroRNA therapeutics for cardiac regeneration. Mini Rev Med Chem 15: 441-451, 2015.

32. Li J, Chan MC, Yu Y, Bei Y, Chen P, Zhou Q, Cheng L, Chen L, Ziegler O, Rowe GC, et al: miR-29b contributes to multiple types of muscle atrophy. Nat Commun 8: 15201, 2017.

33. Horak M, Novak $J$ and Bienertova-Vasku J: Muscle-specific microRNAs in skeletal muscle development. Dev Biol 410: 1-13, 2016.

34. Lagos-Quintana M, Rauhut R, Yalcin A, Meyer J, Lendeckel W and Tuschl T: Identification of tissue-specific microRNAs from mouse. Curr Biol 12: 735-739, 2002.

35. Walden TB, Timmons JA, Keller P, Nedergaard J and Cannon B: Distinct expression of muscle-specific MicroRNAs (myomirs) in brown adipocytes. J Cell Physiol 218: 444-449, 2009.

36. Chen J, Mandel EM, Thomson JM, Wu Q, Callis TE, Hammond SM, Conlon FL and Wang DZ: The role of microRNA-1 and microRNA-133 in skeletal muscle proliferation and differentiation. Nat Genet 38: 228-233, 2006.

37. McCarthy JJ and Esser KA: MicroRNA-1 and microRNA-133a expression are decreased during skeletal muscle hypertrophy. J Appl Physiol (1985) 102: 306-313, 2007.

38. Boutz PL, Chawla G, Stoilov P and Black DL: MicroRNAs regulate the expression of the alternative splicing factor $\mathrm{nPTB}$ during muscle development. Gene Dev 21: 71-84, 2007.

39. Anderson C, Catoe $\mathrm{H}$ and Werner R: MIR-206 regulates connexin43 expression during skeletal muscle development. Nucleic Acids Res 34: 5863-5871, 2006.

40. Kim HK, Lee YS, Sivaprasad U, Malhotra A and Dutta A: Muscle-specific microRNA miR-206 promotes muscle differentiation. J Cell Biol 174: 677-687, 2006.

41. Antoniou A, Mastroyiannopoulos NP, Uney JB and Phylactou LA: MiR-186 inhibits muscle cell differentiation through myogenin regulation. J Biol Chem 289: 3923-3935, 2014.

42. Guan L, Hu X, Liu L, Xing Y, Zhou Z, Liang X, Yang Q, Jin S, Bao J, Gao H, et al: bta-miR-23a involves in adipogenesis of progenitor cells derived from fetal bovine skeletal muscle. Sci Rep 7: 43716, 2017. 
43. Mercatelli N, Fittipaldi S, De Paola E, Dimauro I, Paronetto MP, Jackson MJ and Caporossi D: MiR-23-TrxR1 as a novel molecular axis in skeletal muscle differentiation. Sci Rep 7: 7219, 2017

44. Hou L, Xu J, Jiao Y, Li H, Pan Z, Duan J, Gu T, Hu C and Wang C: MiR-27b promotes muscle development by inhibiting MDFI expression. Cell Physiol Biochem 46: 2271-2283, 2018.

45. Liu C, Wang M, Chen M, Zhang K, Gu L, Li Q, Yu Z, Li N and Meng Q: MiR-18a induces myotubes atrophy by down-regulating IgfI. Int J Biochem Cell Biol 90: 145-154, 2017.

46. Liu C, Chen M, Wang M, Pi W, Li N and Meng Q: MiR-18a regulates myoblasts proliferation by targeting Fgf1. PLoS One 13: e201551, 2018.

47. Chen J, Tao Y, Li J, Deng Z, Yan Z, Xiao X and Wang DZ: MicroRNA-1 and microRNA-206 regulate skeletal muscle satellite cell proliferation and differentiation by repressing Pax7. J Cell Biol 190: 867-879, 2010.

48. Kallen AN, Zhou XB, Xu J, Qiao C, Ma J, Yan L, Lu L, Liu C, Yi JS and Zhang H: The imprinted H19 lncRNA antagonizes let-7 microRNAs. Mol Cell 52: 101-112, 2013.

49. Wang G, Wang Y, Xiong Y, Chen XC, Ma ML, Cai R, Gao Y, Sun YM, Yang GS and Pang WJ: Sirt1 AS lncRNA interacts with its mRNA to inhibit muscle formation by attenuating function of miR-34a. Sci Rep 6: 21865, 2016.

50. Chen R, Jiang T, Lei S, She Y, Shi H, Zhou S, Ou J and Liu Y: Expression of circular RNAs during $\mathrm{C} 2 \mathrm{C} 12$ myoblast differentiation and prediction of coding potential based on the number of open reading frames and N6-methyladenosine motifs. Cell Cycle 17: 1832-1845, 2018.
51. Li F, Li X, Peng X, Sun L, Jia S, Wang P, Ma S, Zha H, Yu Q and Huo H: Ginsenoside Rg1 prevents starvation-induced muscle protein degradation via regulation of $\mathrm{AKT} / \mathrm{mTOR} / \mathrm{FoxO}$ signaling in C2C12 myotubes. Exp Ther Med 14: 1241-1247, 2017.

52. The Ministry of Science and Technology of the People's Republic of China: Guidance suggestions for the care and use of laboratory animals. Sep 30, 2006.

53. Livak KJ and Schmittgen TD: Analysis of relative gene expression data using real-time quantitative PCR and the 2(-Delta Delta C(T)) method. Methods 25: 402-408, 2001.

54. Kim W, Kim J, Park H and Jeon J: Development of microfluidic stretch system for studying recovery of damaged skeletal muscle cells. Micromachines (Basel) 9: E671, 2018

55. von Roretz C, Beauchamp P, Di Marco S and Gallouzi I: HuR and myogenesis: Being in the right place at the right time. Biochim Biophys Acta 1813: 1663-1667, 2011.

56. Chen CM, Kraut N, Groudine M and Weintraub H: I-mf, a novel myogenic repressor, interacts with members of the MyoD family. Cell 86: 731-741, 1996.

This work is licensed under a Creative Commons Attribution-NonCommercial-NoDerivatives 4.0 International (CC BY-NC-ND 4.0) License. 